\title{
The Palaeoindian debate
}

\section{New data suggest that humans occupied Chile as long ago as 33,000 years ago. But will this end controversy about the date of the first human colonization of the Americas?}

THE controversy over the age of the first human colonization of the Americas continues: at the latest meeting on the subject (Smithsonian Institution, Washington DC; September 1987) it became clear that there is still no consensus. Many do not believe humans lived in the Americas until 11,500 years ago, when sites with fluted spear points are abundant and widespread from Alaska to Patagonia. Others argue - in decreasing order of plausibility — for man's arrival somewhere between 30,000 and 40,000 years ago, 200,000 years ago (the notorious Calico Hills site), or even $3,000,000$ years ago (at Toca de Esperança in Brazil). The more extreme claims are generally discounted, and the serious debate concerns just a few sites between 20,000 and 40,000 years ago.

In 1986, when the case for human presence at Boqueirão da Pedra Furada, in Brazil, around 32,000 years ago was published in Nature ${ }^{1.2}$, informal opinions among archaeologists ranged from acceptance to complete disbelief. Now, on page 150 of this issue, Dillehay and Collins present new data from Monte Verde, Chile, suggesting human occupation there about 33,000 years ago. But will the sceptics be convinced? The stratigraphy of the site is unambiguous; the radiocarbon dates conform to geological predictions; and there are possible fire hearths - but the artefact sample is dangerously small ( 8 tools plus 18 naturally split stones imported from outside the area). It is not a good sample, but individually the stone items are similar to those from the upper level, dated to about 13,000 years ago and associated with man-made structures.

In much of the debate about the first Americans, two very different questions have become confused. One is that of the oldest evidence for human presence in the New World. The answer could, in theory, consist of a fire hearth, a butchered carcass, a change in the pollen spectrum, or a piece of stone transported by human agency. Confusion sets in when this question is mixed with that of what the oldest American artefacts look like. Some archaeologists expect to find standardized tool types, analogous to those of the Old World Palaeolithic or the Clovis period in America, whereas others expect the earliest industries to be of a more opportunistic kind, with any suitable piece of stone serving as a tool.

This division within the profession is as much psychological as archaeological, but it affects the way in which potentially early stone work is evaluated. Some will settle for nothing less than the presence of 'types', or at least of patterned repetition, which is impossible to recognize in a very small sample; others accept more circumstantial kinds of evidence (use-damage, or deliberate selection of raw materials) as sufficient proof of man's presence.

In the case of Monte Verde, readers must decide for themselves. The authors are cautious, claiming only that the site is "a strong contender" for very early status. On previous form, the likelihood is that Monte Verde will not change any of the demarcation lines.

The fact that, after so many years of endeavour, no site older than 12,000 years ago has won universal acceptance, provokes concern about the nature of archaeological 'proof' and about how sites are validated. It is significant that so few archaeologists have changed sides, in either direction, during the past 20 years. Does this mean that the evidence is not yet good enough? Edmund Leach, a leading anthropologist, has said": "Justification in terms of scientific methodology is in part self-deception, for when the figures turn out wrong the true believer will always shuffle the figures; when contrary evidence turns up he throws doubt upon the credentials of the investigator."

Although archaeology likes to masquerade as a science, its objectives are not fundamentally scientific and it does not behave in the same way as physics or biochemistry'. In the 'real' sciences, validation comes through replication of experimental results, but in archaeology this is impossible. Excavation destroys the evidence; once a site is dug we have only the excavator's word for what was found there. In consequence there is always room for doubt. No excavation can ever satisfy the criterion of 100 per cent proof, nor can excavators anticipate what questions will be asked in 20 years' time.

In practice, what saves archaeology from complete chaos is the fact that there is some duplication. When a series of comparable sites has been tested, a general pattern emerges, becomes the new orthodoxy, and governs expectations. This process of validation does not work for the truly unique site and, unfortunately, all the problematic early American sites belong to this one-off category. They are few in number, set in different environments, and spread over several millennia. Research on Early Man in the Americas is still in a pre-consensus stage, and opinion could go either way. Validation, in the end, depends on the collective professional verdict, itself based on subjective assessment of the investigator's competence and honesty, and the inherent 'reasonableness' of his results.

If the nature of the evidence is a cause for concern, so too is the make-up of the jury. For historical reasons, the international opinion-formers in Palaeoindian studies are mostly English-speaking and based in North America, where convincing early sites have not been found. Inevitably, there are behind-the-scenes mutterings about sour grapes, nationalism, double standards of proof, and a view that some sites (and some researchers) are required to pass more stringent tests than others. True or not, the fact that many people believe these views is disquieting. It is right that new and controversial ideas should be rigorously examined; it was, after all, this kind of persistent scepticism that disposed of the claims of the Old Crow sites ${ }^{6}$ and gave us the correct (Holocene) age of the California skeletons ${ }^{7}$. Does anyone seriously think that a potentially early site dug by, say, a graduate student from Paraguay and published (in Spanish) in a local journal will receive the same kind of assessment as an excavation directed by an established figure, endorsed by other specialists, then published in an international periodical?

There is no obvious way out of this dilemma. Further research will eventually resolve the Palaeoindian question, but the wider problem of how to validate the oneoff site will always be with us. Even if there is no solution, I believe we should admit we have a problem and should try to agree what constitutes an acceptable standard of proof when the 100 per cent level is unattainable. Clarifying standards need not mean lowering them. In the meantime we still have to make interim judgements on the sites we have got. Warwick Bray

1. Guidon, N. \& Delibrias, G. Nature 321, 769-771 (1986). 2. Bray, W. Nature 321, 76 (1986)

3. Dillehay, T.D. \& Collins, M.B. Nature 332, 150-152 (1988).

4. Leach, E. The Explanation of Culture Change (ed. Renfrew, C.) 762 (Duckworth, London, 1973)

5. Reece, R. Inst. Archaeol. Bull. 24, 191-203 (University College, London, 1987).

6. Nelson, D.E. et al. Science 232, 749 (1986).

7. Bada. J.L. Am. Antiquity 50, 645 (1985).

Warwick Bray is at the University of London Institute of Archaeology, 31-34 Gordon Square, London WCIH OPY, UK 